\title{
miR319, miR390, and miR393 Are Involved in Aluminum Response in Flax (Linum usitatissimum L.)
}

\author{
Alexey A. Dmitriev, ${ }^{1}$ Anna V. Kudryavtseva, ${ }^{1}$ Nadezhda L. Bolsheva, \\ Alexander V. Zyablitsin, ${ }^{1}$ Tatiana A. Rozhmina, ${ }^{1,2}$ Natalya V. Kishlyan, ${ }^{2}$ \\ George S. Krasnov, ${ }^{1}$ Anna S. Speranskaya, ${ }^{1,3}$ Anastasia A. Krinitsina, ${ }^{3}$ \\ Asiya F. Sadritdinova, ${ }^{1}$ Anastasiya V. Snezhkina, ${ }^{1}$ Maria S. Fedorova, ${ }^{1}$ \\ Olga Yu. Yurkevich, ${ }^{1}$ Olga V. Muravenko, ${ }^{1}$ \\ Maxim S. Belenikin, ${ }^{1,3}$ and Nataliya V. Melnikova ${ }^{1}$ \\ ${ }^{1}$ Engelhardt Institute of Molecular Biology, Russian Academy of Sciences, Moscow 119991, Russia \\ ${ }^{2}$ All-Russian Research Institute for Flax, Torzhok 172002, Russia \\ ${ }^{3}$ Faculty of Biology, Lomonosov Moscow State University, Moscow 119991, Russia
}

Correspondence should be addressed to Nataliya V. Melnikova; mnv-4529264@yandex.ru

Received 23 September 2016; Revised 6 January 2017; Accepted 29 January 2017; Published 19 February 2017

Academic Editor: Xiaobai Li

Copyright (C) 2017 Alexey A. Dmitriev et al. This is an open access article distributed under the Creative Commons Attribution License, which permits unrestricted use, distribution, and reproduction in any medium, provided the original work is properly cited.

Acid soils limit agricultural production worldwide. Major reason of crop losses in acid soils is the toxicity of aluminum (Al). In the present work, we investigated expression alterations of microRNAs in flax (Linum usitatissimum L.) plants under Al stress. Flax seedlings of resistant (TMP1919 and G1071/4_k) and sensitive (Lira and G1071/4_o) to Al cultivars and lines were exposed to $\mathrm{AlCl}_{3}$ solution for 4 and 24 hours. Twelve small RNA libraries were constructed and sequenced using Illumina platform. In total, 97 microRNAs from 18 conserved families were identified. miR319, miR390, and miR393 revealed expression alterations associated with $\mathrm{Al}$ treatment of flax plants. Moreover, for miR390 and miR393, the alterations were distinct in sensitive and resistant to $\mathrm{Al}$ genotypes. Expression level changes of miR319 and miR390 were confirmed using qPCR analysis. In flax, potential targets of miR319 are TCPs, miR390-TAS3 and GRF5, and miR393-AFB2-coding transcripts. TCPs, TAS3, GRF5, and AFB2 participate in regulation of plant growth and development. The involvement of miR319, miR390, and miR393 in response to $\mathrm{Al}$ stress in flax was shown here for the first time. We speculate that these microRNAs play an important role in $\mathrm{Al}$ response via regulation of growth processes in flax plants.

\section{Introduction}

Acid soils result in decrease of agricultural production all over the world [1]. Toxicity of aluminum (Al) is a major reason of crop losses in acid soils [2]. Different mechanisms of plant response to $\mathrm{Al}$ stress were identified: organic acid exudation by roots to chelate $\mathrm{Al}$ ions in soil, detoxification of $\mathrm{Al}$ in plants via chelation or transportation into the vacuole, modifications of cell wall to alter $\mathrm{Al}$ binding with its components, and so forth [3-5].

MicroRNA (miRNA) negatively regulates gene expression and in this way controls numerous biological processes in plants [6], including stress response [7-9]. Gene expression regulation via miRNA was revealed as one of the mechanisms of response to $\mathrm{Al}$ in different plant species [10-12]. However, there is no data on involvement of miRNAs in response to Al stress in important agricultural plant, flax (Linum usitatissimum L.). Flax fiber is utilized in textile industry; flax seeds are used for production of oil, linoleum, food, and pharmaceutical products [13-15]. Flax genetics and epigenetics are in the focus of research interest [16-20]. In the previous works on flax, the involvement of miRNAs in response to saline and alkaline stresses [21] and excessive or deficient nutrition [22-24] was shown. 
In the present work, we performed high-throughput sequencing of flax small RNAs under normal conditions and Al exposure to identify miRNAs, whose expression was altered in response to aluminum stress, and suggested potential targets of these miRNAs in flax to speculate on affected signaling pathways.

\section{Materials and Methods}

2.1. Plant Material. L. usitatissimum plants of resistant (TMP1919 and G1071/4_k) and sensitive (Lira and G1071/4_o) to aluminum cultivars and lines were used in the present study. Seeds germinated on filter paper soaked with distilled water for 5 days. Then seedlings were transferred to falcon tubes with filter paper soaked with a $0.5 \mathrm{mM} \mathrm{CaCl}_{2}$ solution at $\mathrm{pH} 4.5$ for $24 \mathrm{~h}$ before being exposed to a $0.5 \mathrm{mM} \mathrm{CaCl}$ solution ( $\mathrm{pH} 4.5)$ containing $0(\mathrm{~N})$ or $500 \mu \mathrm{M} \mathrm{AlCl}_{3}$ for $4(\mathrm{Al}$ 4 ) and 24 (Al-24) hours. Roots were cut off and immediately frozen in liquid nitrogen. Plant samples were stored at $-70^{\circ} \mathrm{C}$.

Total RNA was extracted from roots of flax plants using RNA MicroPrep kit (Zymo Research, USA). RNA quality and concentration were determined by Qubit 2.0 fluorometer (Life Technologies, USA) and Agilent 2100 Bioanalyzer (Agilent Technologies, USA). For further analysis, only RNA samples with RNA Integrity Number (RIN) value not less than 8.0 were used.

2.2. Flax Small RNA Sequencing. Library preparation was performed using Illumina TruSeq small RNA preparation kit (Illumina, USA) in compliance with manufacturer's protocol. Twelve libraries from pooled plant samples were obtained: $\mathrm{N}, \mathrm{Al}-4$, and Al-24 for each of four cultivars/lines (TMP1919, G1071/4_k, G1071/4_o, and Lira). Library quality was evaluated using Agilent 2100 Bioanalyzer (Agilent Technologies). The sequencing was performed on Genome Analyzer IIx (Illumina).

2.3. Bioinformatics Analysis of miRNAs. Low-quality reads and adapter reads were removed from raw sequencing data using Trimmomatic [25]. For further analysis, we used cleaned reads with abundance six or more. To identify conserved miRNAs in flax, small RNA sequences were aligned with known matured miRNA sequences from miRBase 21.0 [26]. Prediction of miRNA targets was performed using psRNATarget server [27] with default parameters using identified L. usitatissimum transcripts [16, 28].

miRNA levels were normalized to obtain reads per million (RPM) values. The comparison of miRNA expression levels in Al-4 and Al-24 libraries with $\mathrm{N}$ library was performed using fold change parameter: $\mathrm{FC}=\mathrm{RPM}$ in $\mathrm{Al}-$ 4 or Al-24/RPM in N. $P$ values were calculated using $\chi^{2}$ test with Benjamini-Hochberg multiple testing correction. Changes were considered significant if FC or $1 / \mathrm{FC}$ were 1.5 or higher, that is, absolute value of $\log _{2} \mathrm{FC} \geq 0.58$.

2.4. Quantitative PCR ( $q P C R$ ) Analysis of miRNA Expression. We performed qPCR analysis to evaluate expression of miR319 and miR390. TaqMan MicroRNA Assays aau-miR319 and ath-miR390a (Thermo Fisher Scientific, USA) were used. Reverse transcription was performed in $15 \mu \mathrm{L}$ reaction containing 1x RT primer (Thermo Fisher Scientific), $200 \mathrm{U}$ of RevertAid Reverse Transcriptase (Thermo Fisher Scientific), 1x Reverse Transcription Buffer, $250 \mathrm{nM}$ of dNTPs, and $10 \mathrm{ng}$ of total RNA using the following program: $16^{\circ} \mathrm{C}$ for $30 \mathrm{~min}$, $42^{\circ} \mathrm{C}$ for $30 \mathrm{~min}$, and $85^{\circ} \mathrm{C}$ for $5 \mathrm{~min}$. QPCR was performed using the 7500 Real-Time PCR System in a $20 \mu \mathrm{L}$ reaction mix containing 1x PCR mix (GenLab, Russia), $250 \mathrm{nM}$ of dNTPs, $2 \mathrm{U}$ of polymerase (GenLab), Rox dye, and RT product using the following program: $95^{\circ} \mathrm{C}$ for $15 \mathrm{~min}, 40$ cycles of $95^{\circ} \mathrm{C}$ for $15 \mathrm{~s}$, and $60^{\circ} \mathrm{C}$ for $60 \mathrm{~s}$. Three technical replicates were performed. For the evaluation of expression level alterations, $\Delta \Delta C_{t}{ }^{\text {eff }}$ values, which are directly proportional to the expression level changes, were calculated $[29,30]$. ETIF3H and ETIF3E were chosen as the reference genes for the qPCR data analysis [24, 29, 31]. All the calculations were done using the Analysis of Transcription of Genes software [24, 32]. Correlation between high-throughput sequencing $\left(\log _{2} \mathrm{FC}\right)$ and $\mathrm{qPCR}\left(\Delta \Delta C_{t}{ }^{\text {eff }}\right)$ expression data was evaluated using Spearman's correlation coefficient.

\section{Results and Discussion}

Seedlings of resistant (TMP1919 and G1071/4_k) and sensitive (Lira and G1071/4_o) to Al flax cultivars and lines were exposed to Al for 4 and 24 hours. Twelve small RNA libraries were constructed and sequenced on Illumina GAIIx. In total, about 40 million raw reads were obtained. All the sequences were deposited in the European Nucleotide Archive, accession number PRJEB15342.

Search for flax miRNAs using miRBase sequences led to identification of 97 potential flax miRNAs from 18 conserved families: miR156, miR157, miR159, miR160, miR162, miR164, miR165, miR166, miR167, miR168, miR171, miR319, miR390, miR393, miR394, miR396, miR398, and miR408 (Supplementary Table 1 in Supplementary Material available online at https://doi.org/10.1155/2017/4975146). Among these miRNAs, the search for Al responsive miRNAs was performed. To reveal common trends specific to flax plants, we evaluated expression alterations after 4 and 24 hours of $\mathrm{Al}$ treatment using pooled data for all examined cultivars and lines $\left(\log _{2} \mathrm{FC}\right.$ values are represented in Table 1).

After 4 hours of $\mathrm{Al}$ exposure, we observed significant (absolute value of $\log _{2} \mathrm{FC} \geq 0.58$ ) upregulation of miR164, miR319, miR393, and miR394 and downregulation of miR159, miR167, and miR408. After 24 hours of Al exposure, significant expression decrease was revealed for all 18 miRNA families except miR393. Thus, after 4 hours of Al treatment, miRNA levels of different families were increased, decreased, or stable. However, after 24 hours of Al exposure, expression was decreased for almost all miRNA families.

We also performed analysis of expression alterations of miRNA families in individual cultivars and lines to identify trends in resistant and sensitive to Al flax plants (Supplementary Table 2). $\log _{2}$ FC values are represented in Table 1 . Some of the miRNAs showed opposite directions of expression alterations in studied flax cultivars and lines. As seen from Table 1, after 4 hours of Al exposure, miR156, miR157, miR162, 
TABLE 1: Expression alterations of miRNAs after 4 and 24 hours of Al treatment in resistant (TMP1919 and G1071/4_k) and sensitive (G1071/4_o and Lira) flax cultivars and lines.

\begin{tabular}{|c|c|c|c|c|c|c|c|c|c|c|}
\hline \multirow{3}{*}{ miRNA family } & \multicolumn{10}{|c|}{$\log _{2} \mathrm{FC}$} \\
\hline & \multicolumn{2}{|c|}{ TMP1919 } & \multicolumn{2}{|c|}{ G1071/4_k } & \multicolumn{2}{|c|}{ G1071/4_o } & \multicolumn{2}{|c|}{ Lira } & \multicolumn{2}{|c|}{ All samples } \\
\hline & $\mathrm{Al}-4$ & Al-24 & $\mathrm{Al}-4$ & $\mathrm{Al}-24$ & $\mathrm{Al}-4$ & $\mathrm{Al}-24$ & $\mathrm{Al}-4$ & $\mathrm{Al}-24$ & $\mathrm{Al}-4$ & $\mathrm{Al}-24$ \\
\hline miR156 & 0.77 & 0.29 & -1.79 & -2.16 & 0.20 & -1.58 & 0.74 & -0.87 & -0.42 & -1.44 \\
\hline miR157 & 0.79 & 0.36 & -1.40 & -1.51 & 0.59 & -1.93 & -0.52 & 0.20 & -0.26 & -0.90 \\
\hline miR159 & -2.81 & -1.57 & -0.11 & -1.97 & -0.51 & -2.17 & 0.11 & 0.66 & -0.62 & -1.13 \\
\hline $\operatorname{miR} 160$ & -0.23 & -1.00 & 12.13 & 0.00 & -0.30 & -2.28 & -1.22 & -0.74 & -0.35 & -1.40 \\
\hline miR162 & 1.09 & -0.86 & -0.92 & -0.29 & -0.88 & -1.94 & -1.43 & -1.78 & -0.47 & -1.04 \\
\hline miR164 & 1.27 & -1.18 & 0.15 & -1.72 & 0.50 & -2.40 & -2.49 & 0.46 & 0.61 & -0.98 \\
\hline miR165 & 1.62 & -0.84 & -1.98 & -3.16 & 0.19 & -1.10 & 0.54 & -1.86 & -0.34 & -2.13 \\
\hline miR166 & 1.13 & -1.19 & -1.75 & -2.23 & 0.27 & -1.60 & -0.39 & -2.33 & -0.36 & -1.98 \\
\hline miR167 & -0.65 & -1.46 & -1.84 & -15.07 & -0.32 & -2.34 & -2.07 & -0.22 & -0.78 & -1.54 \\
\hline miR168 & 0.20 & -1.14 & -0.39 & -1.81 & -0.30 & -1.60 & -0.60 & -1.25 & -0.28 & -1.41 \\
\hline miR171 & 0.94 & 0.31 & -2.36 & -1.78 & -1.22 & -2.60 & 13.02 & 0.00 & -0.01 & -0.95 \\
\hline $\operatorname{miR} 319$ & 1.16 & -0.65 & 0.22 & -2.23 & 0.28 & -2.04 & 0.45 & -1.29 & 0.58 & -1.40 \\
\hline $\operatorname{miR} 390$ & 1.27 & -0.01 & 0.85 & -0.84 & -0.78 & -3.04 & -0.35 & -1.77 & 0.17 & -1.38 \\
\hline miR393 & 1.66 & 0.20 & 1.10 & 0.07 & -0.46 & -1.43 & -0.10 & 0.51 & 0.61 & -0.33 \\
\hline miR394 & 1.54 & -0.18 & 13.71 & 12.33 & -0.44 & -1.99 & -0.83 & -1.24 & 0.71 & -0.68 \\
\hline miR396 & 0.40 & -1.45 & -0.99 & -1.90 & -0.23 & -1.51 & -1.00 & -1.26 & -0.32 & -1.45 \\
\hline miR398 & -0.06 & -1.22 & 0.00 & 0.00 & 0.38 & -0.51 & 0.56 & -2.83 & 0.47 & -1.78 \\
\hline miR408 & -0.17 & -0.37 & -0.35 & -1.86 & 1.40 & 1.98 & -2.20 & -3.61 & -0.82 & -0.86 \\
\hline
\end{tabular}

miR165, miR166, and miR171 were significantly upregulated in one of the resistant genotypes and significantly downregulated in the other one. The same was observed for miR171 and miR408 in sensitive genotypes. We suggested that these miRNAs with opposite regulation under $\mathrm{Al}$ stress in resistant or sensitive cultivars and lines do not play the key role in flax response to $\mathrm{Al}$. After 24 hours of $\mathrm{Al}$ treatment, the majority of miRNAs was downregulated in all 4 cultivars and lines.

Definite regularities were revealed for expression alterations of miR319, miR390, and miR393 families. The level of miR319 was changed in a similar way in resistant and sensitive to Al cultivars and lines: expression was increased after 4 hours of $\mathrm{Al}$ exposure ( $\log _{2} \mathrm{FC}$ varied from 0.22 to 1.16 ) and decreased after 24 hours ( $\log _{2} \mathrm{FC}$ varied from -0.65 to -2.23; Figure 1). miR390 level was decreased after 4 hours of $\mathrm{Al}$ exposure in sensitive to $\mathrm{Al}$ flax genotypes $\left(\log _{2} \mathrm{FC}\right.$ was -0.78 for G1071/4_o and -0.35 for Lira), but increased in resistant genotypes $\left(\log _{2} \mathrm{FC}\right.$ was 1.27 in TMP1919 and 0.85 in G1071/4_k; Figure 1). Moreover, after 24 hours of Al exposure, we revealed retention or moderate downregulation of miR390 in resistant to $\mathrm{Al}$ cultivar and line $\left(\log _{2} \mathrm{FC}\right.$ was -0.01 for TMP1919 and -0.84 for G1071/4_k), but strong downregulation in sensitive cultivar and line ( $\log _{2} \mathrm{FC}$ was -3.04 for G1071/4_o and -1.77 for Lira). miR393 was upregulated in resistant to $\mathrm{Al}$ genotypes ( $\log _{2} \mathrm{FC}$ was 1.66 for TMP1919 and 1.10 for G1071/4_k), but slightly decreased in sensitive to $\mathrm{Al}$ genotypes $\left(\log _{2} \mathrm{FC}\right.$ was -0.46 for G1071/4_o and -0.10 for Lira) after 4 hours of Al exposure (Figure 1). After 24 hours of $\mathrm{Al}$ exposure, miR393 level was stable in resistant to $\mathrm{Al}$ genotypes ( $\log _{2} \mathrm{FC}$ was 0.20 for TMP1919 and 0.07 for G1071/4_k) and deregulated in sensitive to $\mathrm{Al}$ genotypes ( $\log _{2}$ FC was -1.43 for G1071/4_o and 0.51 for Lira).

For validation of high-throughput sequencing data, expression of miR319 and miR390 was evaluated using qPCR. RNA samples of flax plants, which were used for highthroughput sequencing and were taken into qPCR analysis. The data obtained by qPCR and high-throughput sequencing methods were highly consistent: Spearman's correlation coefficient was 0.68 for miR319 and 0.76 for miR390 $(P<0.05$; Figure 2).

In plants, miR319, miR390, and miR393 families have been identified as Al responsive [10, 11]. For miR319, both upregulation [33] and downregulation [34] were revealed in Medicago truncatula in response to Al stress. miR390 was upregulated in wild soybean under $\mathrm{Al}$ exposure [35]. However, in M. truncatula, miR390 was slightly downregulated after short-term Al treatment and was significantly upregulated after long-term one [34]. For miR393, upregulation was revealed in common bean roots in response to Al treatment for 24 hours [36], and downregulation in rice roots after 8 hours of Al treatment [37]. Opposite directions of the alterations of miRNA levels could be associated with different time of $\mathrm{Al}$ treatment or diverse resistance of examined genotypes to $\mathrm{Al}$ stress.

In previous flax studies, potential targets for some miRNAs from miR319, miR390, and miR393 families were predicted [21, 38, 39]. Here, we performed target prediction for flax highly-expressed miRNAs from miR319, miR390, and miR393 families (Supplementary Table 3).

For miR319, the following targets were predicted by us in flax: transcripts encoding cysteine-rich secretory proteins, 


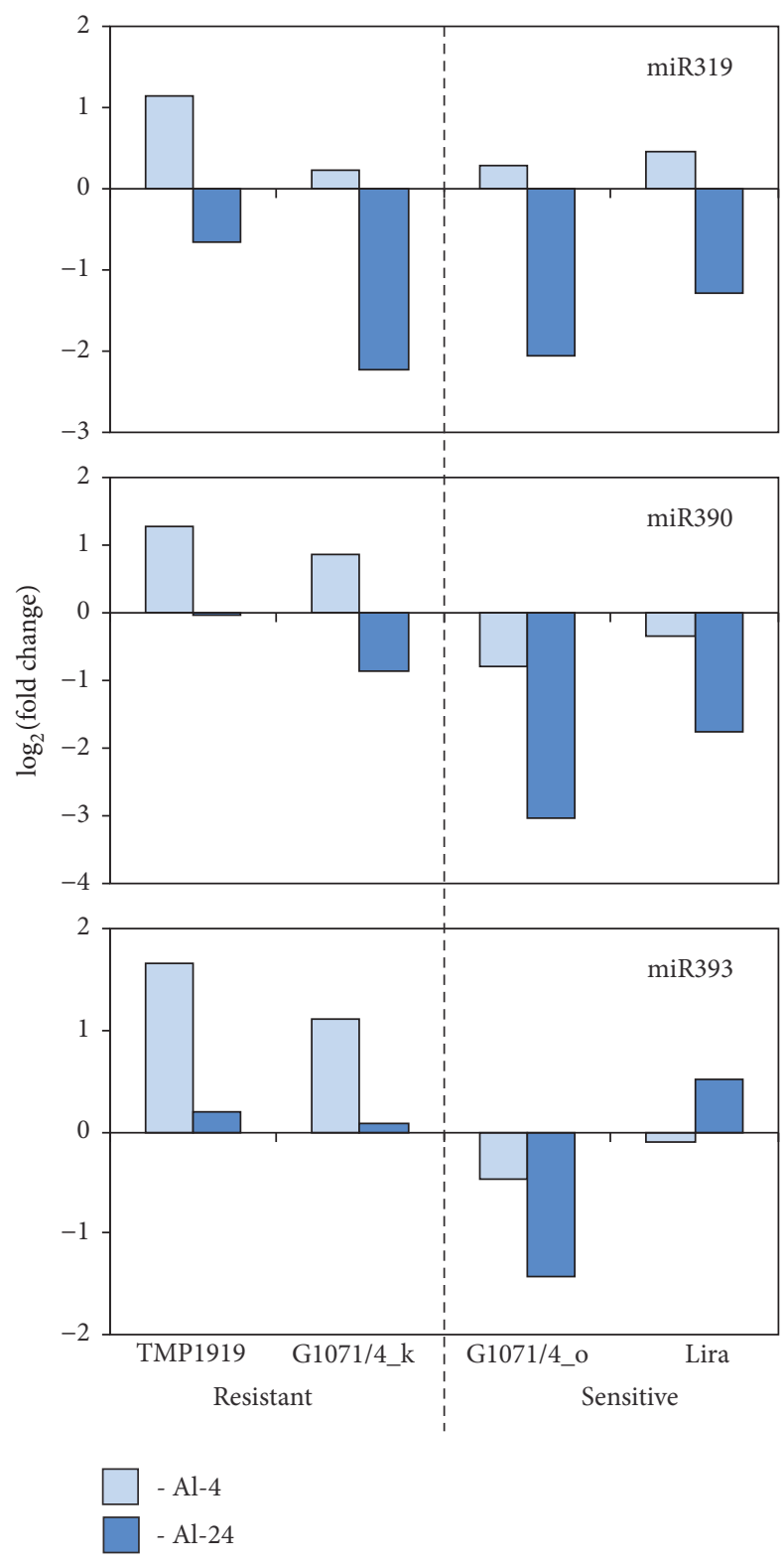

FIgURE 1: Expression alterations of miR319, miR390, and miR393 in resistant and sensitive flax cultivars and lines under $\mathrm{Al}$ stress.

antigen 5 , pathogenesis-related 1 protein; myb domain protein 65 (MYB65); Teosinte Branched/Cycloidea/PCF transcription factor 3 (TCP3) superfamily protein; TCP family transcription factor 4; $\mathrm{ABC}$ transporter. Within predicted targets of miR319, Lus10002195 and Lus10000463 transcripts encoding TCP3 and TCP4 are the most interesting. It was previously shown that miR319 targets mRNA of TCP transcription factors, which control plant growth and development [40-42]. We suggest that the most probable target of miR319 in flax is also TCPs.

For miR390, predicted targets in flax were transcripts encoding leucine-rich receptor-like protein kinase family protein; protein kinase superfamily protein; growth-regulating factor 5 (GRF5); root hair specific 10 (RHS10); poor homologous synapsis 1 (PHS1); leucine-rich repeat (LRR) family protein; TAS3. Transcript Lus10009533 encoding GRF5 was one of the potential targets of miR390. GRFs play important role in plant developmental processes and growth under adverse environments and could be regulated by TCP4 [43]. TAS3-coding transcript, genolin_c19878 from L. usitatissimum unigene library, was also predicted as potential target of miR390. In other plant species, miR390 initiates tasiRNA (trans-acting small interfering RNA) biogenesis via cleavage or interaction with TAS3 transcript. TAS3 tasiRNAs negatively regulate ARFs (auxin response factors) that is necessary for proper plant development [44-48]. We suppose that TAS3 and GRF5 are the most likely targets of miR390 in flax.

Auxin signaling F-box 2 (AFB2), zinc finger (C3HC4type RING finger) family protein, and pol-like 5 (PLL5) transcripts were predicted as targets of miR393 in flax. Lus10031991 and Lus10035160 encoding AFB2 are the most interesting targets of miR393. It was previously reported that targets of miR393 are AFB1 (auxin f-box protein1), AFB2, and AFB3, which are involved in auxin signaling [32, 49-51]. We speculate that miR393 probably regulates AFB2 expression in flax.

Thus, expression alterations of miR319, miR390, and miR393, which were revealed as Al-responsive in flax, could affect expression level of a number of key transcripts involved in plant growth and development.

\section{Conclusions}

High-throughput sequencing and qPCR analyses of flax small RNAs allowed us to reveal miRNAs with expression alterations under $\mathrm{Al}$ exposure. Our results suggest the involvement of miR319, miR390, and miR393 in Al response in L. usitatissimum plants. Moreover, we revealed diverse alterations of miR390 and miR393 levels in resistant and sensitive to Al genotypes. We concluded that, in flax, potential targets of miR319 are TCPs, miR390-TAS3 and GRF5, and miR393-AFB2. Thus, we speculate that miR319, miR390, and miR393 play an important role in $\mathrm{Al}$ stress response via regulation of growth and development processes in flax plants.

\section{Competing Interests}

The authors declare that there is no conflict of interests regarding the publication of this paper.

\section{Authors' Contributions}

Alexey A. Dmitriev, Anna V. Kudryavtseva, and Nadezhda L. Bolsheva contributed equally to this work.

\section{Acknowledgments}

This work was financially supported by the Russian Science Foundation, Grant 16-16-00114. The authors thank Lomonosov Moscow State University for the help with plant growing and All-Russian Research Institute for Flax for the selection and provision of seeds. This work was performed 


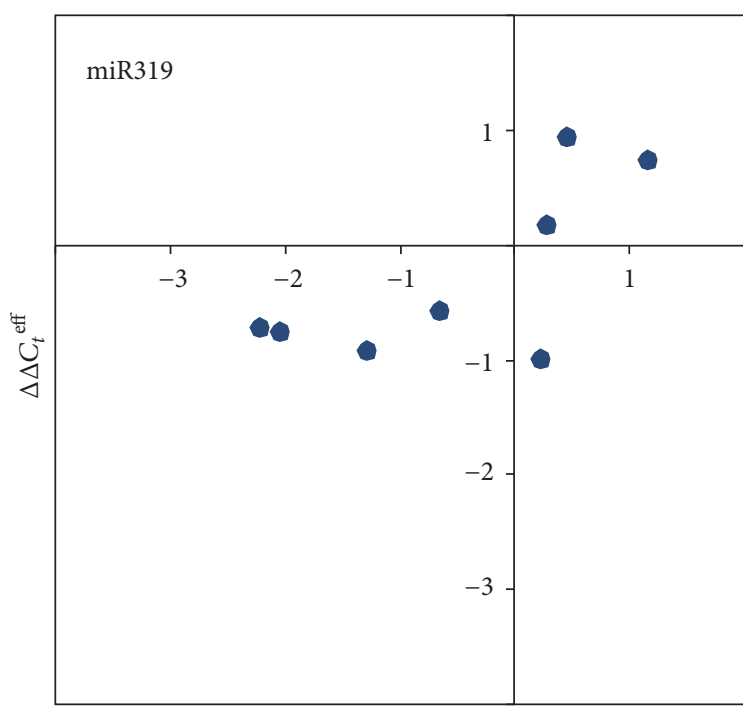

$\log _{2} \mathrm{FC}$

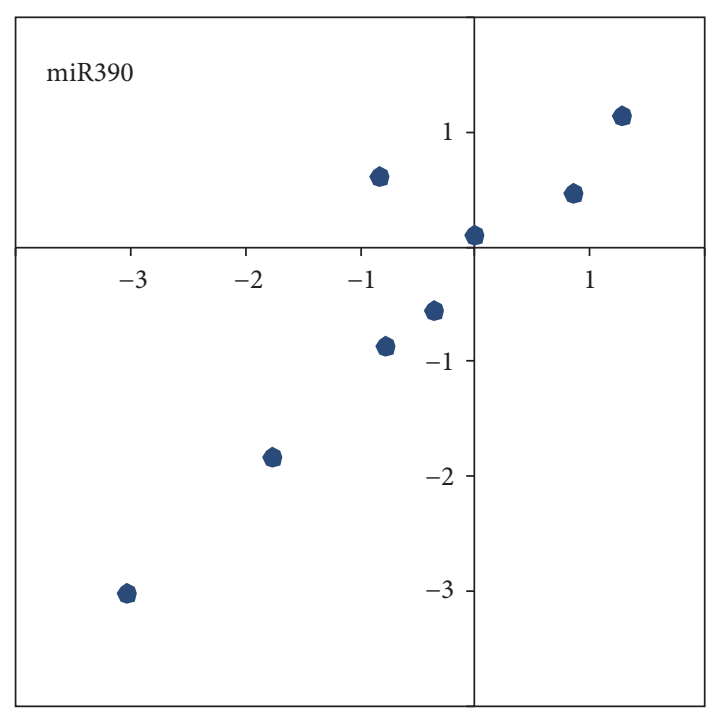

$\log _{2} \mathrm{FC}$

FIGURE 2: Correlation between qPCR $\left(\Delta \Delta C_{t}^{\text {eff }}\right)$ and high-throughput sequencing $\left(\log _{2} \mathrm{FC}\right)$ expression data for miR319 and miR390 in flax cultivars and lines under $\mathrm{Al}$ stress.

using the equipment of "Genome" center of Engelhardt Institute of Molecular Biology (http://www.eimb.ru/rus/ckp/ ccu_genome_c.php).

\section{References}

[1] H. R. von Uexküll and E. Mutert, "Global extent, development and economic impact of acid soils," Plant and Soil, vol. 171, no. 1, pp. 1-15, 1995.

[2] L. V. Kochian, O. A. Hoekenga, and M. A. Piñeros, "How do crop plants tolerate acid soils? Mechanisms of aluminum tolerance and phosphorous efficiency," Annual Review of Plant Biology, vol. 55, pp. 459-493, 2004.

[3] L. V. Kochian, M. A. Piñeros, J. Liu, and J. V. Magalhaes, "Plant adaptation to acid soils: the molecular basis for crop aluminum resistance," Annual Review of Plant Biology, vol. 66, pp. 571-598, 2015.

[4] S. K. Panda, F. Baluska, and H. Matsumoto, "Aluminum stress signaling in plants," Plant Signaling and Behavior, vol. 4, no. 7, pp. 592-597, 2009.

[5] H. Sade, B. Meriga, V. Surapu et al., "Toxicity and tolerance of aluminum in plants: tailoring plants to suit to acid soils," BioMetals, vol. 29, no. 2, pp. 187-210, 2016.

[6] M. W. Jones-Rhoades, D. P. Bartel, and B. Bartel, "MicroRNAs and their regulatory roles in plants," Annual Review of Plant Biology, vol. 57, pp. 19-53, 2006.

[7] N. V. Koroban, A. V. Kudryavtseva, G. S. Krasnov et al., "The role of microRNA in abiotic stress response in plants," Molecular Biology, vol. 50, no. 3, pp. 337-343, 2016.

[8] R. Kumar, "Role of microRNAs in biotic and abiotic stress responses in crop plants," Applied biochemistry and biotechnology, vol. 174, no. 1, pp. 93-115, 2014.

[9] V. Shriram, V. Kumar, R. M. Devarumath, T. S. Khare, and S. H. Wani, "MicroRNAs as potential targets for abiotic stress tolerance in plants," Frontiers in Plant Science, vol. 7, p. 817, 2016.
[10] H. He, L. He, and M. Gu, "Role of microRNAs in aluminum stress in plants," Plant Cell Reports, vol. 33, no. 6, pp. 831-836, 2014.

[11] A. B. Mendoza-Soto, F. Sánchez, and G. Hernández, "MicroRNAs as regulators in plant metal toxicity response," Frontiers in Plant Science, vol. 3, article 105, 2012.

[12] Z. Min Yang and J. Chen, "A potential role of microRNAs in plant response to metal toxicity," Metallomics, vol. 5, no. 9, pp. 1184-1190, 2013.

[13] A. D. Muir and N. D. Westcott, Flax: The Fenus Linum, Taylor \& Francis, London, UK, 2003.

[14] A. Goyal, V. Sharma, N. Upadhyay, S. Gill, and M. Sihag, "Flax and flaxseed oil: an ancient medicine \& modern functional food," Journal of Food Science and Technology, vol. 51, no. 9, pp. 1633-1653, 2014.

[15] K. K. Singh, D. Mridula, J. Rehal, and P. Barnwal, "Flaxseed: a potential source of food, feed and fiber," Critical Reviews in Food Science and Nutrition, vol. 51, no. 3, pp. 210-222, 2011.

[16] Z. Wang, N. Hobson, L. Galindo et al., "The genome of flax (Linum usitatissimum) assembled de novo from short shotgun sequence reads," Plant Journal, vol. 72, no. 3, pp. 461-473, 2012.

[17] N. V. Melnikova, A. V. Kudryavtseva, A. V. Zelenin et al., "Retrotransposon-based molecular markers for analysis of genetic diversity within the Genus Linum," BioMed Research International, vol. 2014, Article ID 231589, 14 pages, 2014.

[18] N. L. Bolsheva, A. V. Zelenin, I. V. Nosova et al., “The diversity of karyotypes and genomes within section syllinum of the genus linum (linaceae) revealed by molecular cytogenetic markers and RAPD analysis," PLoS ONE, vol. 10, no. 4, Article ID e0122015, 2015.

[19] N. Zhang and M. K. Deyholos, "RNASeq analysis of the shoot apex of flax (Linum usitatissimum) to identify phloem fiber specification genes," Frontiers in Plant Science, vol. 7, article no. 950, 2016.

[20] C. Johnson, T. Moss, and C. Cullis, "Environmentally induced heritable changes in flax," Journal of Visualized Experiments, vol. 47, 2011. 
[21] Y. Yu, G. Wu, H. Yuan et al., "Identification and characterization of miRNAs and targets in flax (Linum usitatissimum) under saline, alkaline, and saline-alkaline stresses," BMC Plant Biology, vol. 16, no. 1, article 124, 2016.

[22] N. V. Melnikova, M. S. Belenikin, N. L. Bolsheva et al., "Flax Inorganic Phosphate Deficiency Responsive miRNAs," Journal of Agricultural Science, vol. 6, no. 1, pp. 156-160, 2013.

[23] N. V. Melnikova, A. A. Dmitriev, M. S. Belenikin et al., "Excess fertilizer responsive miRNAs revealed in Linum usitatissimum L," Biochimie, vol. 109, pp. 36-41, 2015.

[24] N. V. Melnikova, A. A. Dmitriev, M. S. Belenikin et al., "Identification, expression analysis, and target prediction of flax genotroph microRNAs under normal and nutrient stress conditions," Frontiers in Plant Science, vol. 7, article 399, 2016.

[25] A. M. Bolger, M. Lohse, and B. Usadel, "Trimmomatic: a flexible trimmer for Illumina sequence data," Bioinformatics, vol. 30, no. 15, pp. 2114-2120, 2014.

[26] A. Kozomara and S. Griffiths-Jones, "miRBase: integrating microRNA annotation and deep-sequencing data," Nucleic Acids Research, vol. 39, S1, pp. D152-D157, 2011.

[27] X. Dai and P. X. Zhao, "PsRNATarget: a plant small RNA target analysis server," Nucleic Acids Research, vol. 39, no. 2, pp. W155W159, 2011.

[28] S. Fenart, Y.-P. A. Ndong, J. Duarte et al., "Development and validation of a flax (Linum usitatissimum L.) gene expression oligo microarray," BMC Genomics, vol. 11, no. 1, article 592, 2010.

[29] A. A. Dmitriev, G. Krasnov, T. Rozhmina et al., "Glutathione S-transferases and UDP-glycosyltransferases are involved in response to aluminum stress in flax," Frontiers in Plant Science, vol. 7, p. 1920, 2016.

[30] A. A. Dmitriev, A. V. Kudryavtseva, G. S. Krasnov et al., "Gene expression profiling of flax (Linum usitatissimum L.) under edaphic stress," BMC Plant Biology, vol. 16, no. 3, 2016.

[31] R. Huis, S. Hawkins, and G. Neutelings, "Selection of reference genes for quantitative gene expression normalization in flax (Linum usitatissimum L.)," BMC Plant Biology, vol. 10, article no. 71, 2010.

[32] G. S. Krasnov, N. Y. Oparina, A. A. Dmitriev et al., "RPN1, a new reference gene for quantitative data normalization in lung and kidney cancer," Molecular Biology, vol. 45, no. 2, pp. 211-220, 2011.

[33] Z. S. Zhou, S. Q. Huang, and Z. M. Yang, "Bioinformatic identification and expression analysis of new microRNAs from Medicago truncatula," Biochemical and Biophysical Research Communications, vol. 374, no. 3, pp. 538-542, 2008.

[34] L. Chen, T. Wang, M. Zhao, Q. Tian, and W.-H. Zhang, "Identification of aluminum-responsive microRNAs in Medicago truncatula by genome-wide high-throughput sequencing," Planta, vol. 235, no. 2, pp. 375-386, 2012.

[35] Q.-Y. Zeng, C.-Y. Yang, Q.-B. Ma, X.-P. Li, W.-W. Dong, and H. Nian, "Identification of wild soybean miRNAs and their target genes responsive to aluminum stress," BMC Plant Biology, vol. 12, article no. 182, 2012.

[36] A. B. Mendoza-Soto, L. Naya, A. Leija, and G. Hernández, "Responses of symbiotic nitrogen-fixing common bean to aluminum toxicity and delineation of nodule responsive microRNAs," Frontiers in Plant Science, vol. 6, article 587, 2015.

[37] J. C. Lima, R. A. Arenhart, M. Margis-Pinheiro, and R. Margis, "Aluminum triggers broad changes in microRNA expression in rice roots," Genetics and Molecular Research, vol. 10, no. 4, pp. 2817-2832, 2011.
[38] G. Neutelings, S. Fénart, A. Lucau-Danila, and S. Hawkins, "Identification and characterization of miRNAs and their potential targets in flax," Journal of Plant Physiology, vol. 169, no. 17, pp. 1754-1766, 2012.

[39] T. Y. Moss and C. A. Cullis, "Computational prediction of candidate micrornas and their targets from the completed Linum ussitatissimum genome and EST database," Journal of Nucleic Acids Investigation, vol. 3, no. 1, article no. e2, 2012.

[40] J. F. Palatnik, E. Allen, X. Wu et al., "Control of leaf morphogenesis by microRNAs," Nature, vol. 425, no. 6955, pp. 257-263, 2003.

[41] C. Schommer, J. M. Debernardi, E. G. Bresso, R. E. Rodriguez, and J. F. Palatnik, "Repression of cell proliferation by miR319regulated TCP4," Molecular Plant, vol. 7, no. 10, pp. 1533-1544, 2014.

[42] A. Nag, S. King, and T. Jack, "miR319a targeting of TCP4 is critical for petal growth and development in Arabidopsis," Proceedings of the National Academy of Sciences of the United States of America, vol. 106, no. 52, pp. 22534-22539, 2009.

[43] M. A. Omidbakhshfard, S. Proost, U. Fujikura, and B. MuellerRoeber, "Growth-regulating factors (GRFs): a small transcription factor family with important functions in plant biology," Molecular Plant, vol. 8, no. 7, article 76, pp. 998-1010, 2015.

[44] M. J. Axtell, C. Jan, R. Rajagopalan, and D. P. Bartel, "A two-hit trigger for siRNA biogenesis in plants," Cell, vol. 127, no. 3, pp. 565-577, 2006.

[45] E. Allen, Z. Xie, A. M. Gustafson, and J. C. Carrington, "microRNA-directed phasing during trans-acting siRNA biogenesis in plants," Cell, vol. 121, no. 2, pp. 207-221, 2005.

[46] X. Adenot, T. Elmayan, D. Lauressergues et al., "DRB4Dependent TAS3 trans-Acting siRNAs Control Leaf Morphology through AGO7," Current Biology, vol. 16, no. 9, pp. 927-932, 2006.

[47] N. Fahlgren, T. A. Montgomery, M. D. Howell et al., "Regulation of AUXIN RESPONSE FACTOR3 by TAS3 ta-siRNA Affects Developmental Timing and Patterning in Arabidopsis," Current Biology, vol. 16, no. 9, pp. 939-944, 2006.

[48] T. A. Montgomery, M. D. Howell, J. T. Cuperus et al., "Specificity of ARGONAUTE7-miR390 interaction and dual functionality in TAS3 trans-acting siRNA formation," Cell, vol. 133, no. 1, pp. 128-141, 2008.

[49] L. Navarro, P. Dunoyer, F. Jay et al., "A plant miRNA contributes to antibacterial resistance by repressing auxin signaling," Science, vol. 312, no. 5772, pp. 436-439, 2006.

[50] A. M. Wójcik and M. D. Gaj, "miR393 contributes to the embryogenic transition induced in vitro in Arabidopsis via the modification of the tissue sensitivity to auxin treatment," Planta, vol. 244, no. 1, pp. 231-243, 2016.

[51] K. Mockaitis and M. Estelle, "Auxin receptors and plant development: a new signaling paradigm," Annual Review of Cell and Developmental Biology, vol. 24, pp. 55-80, 2008. 

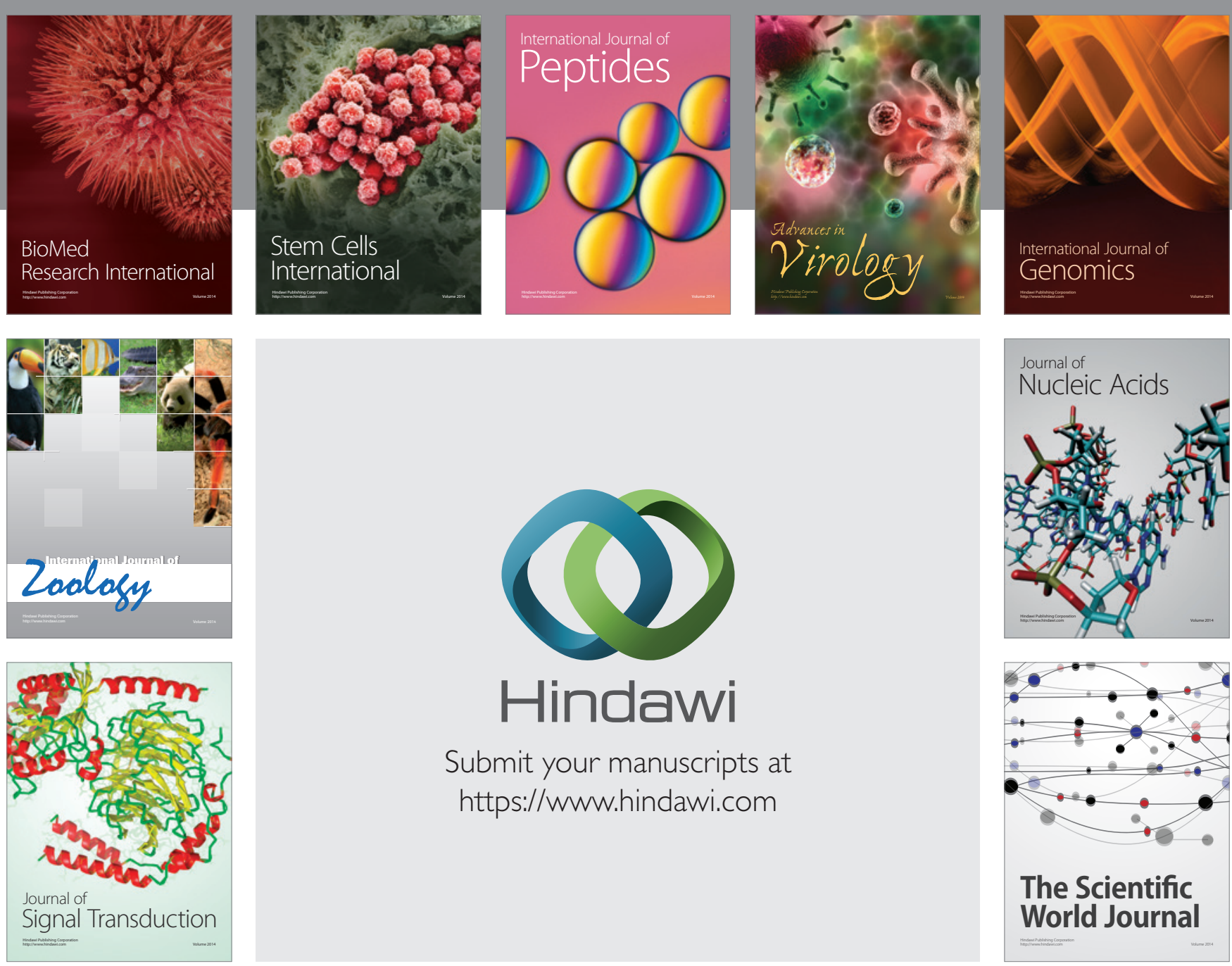

Submit your manuscripts at

https://www.hindawi.com
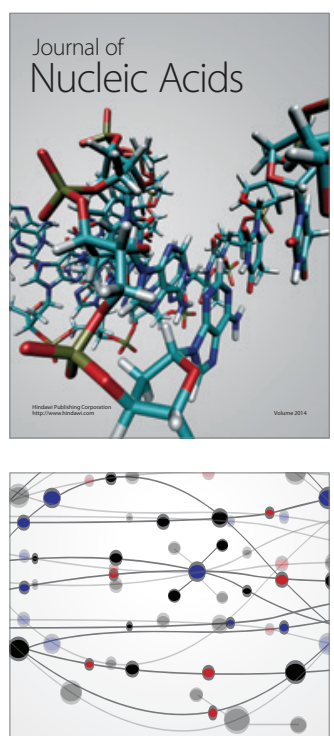

The Scientific World Journal
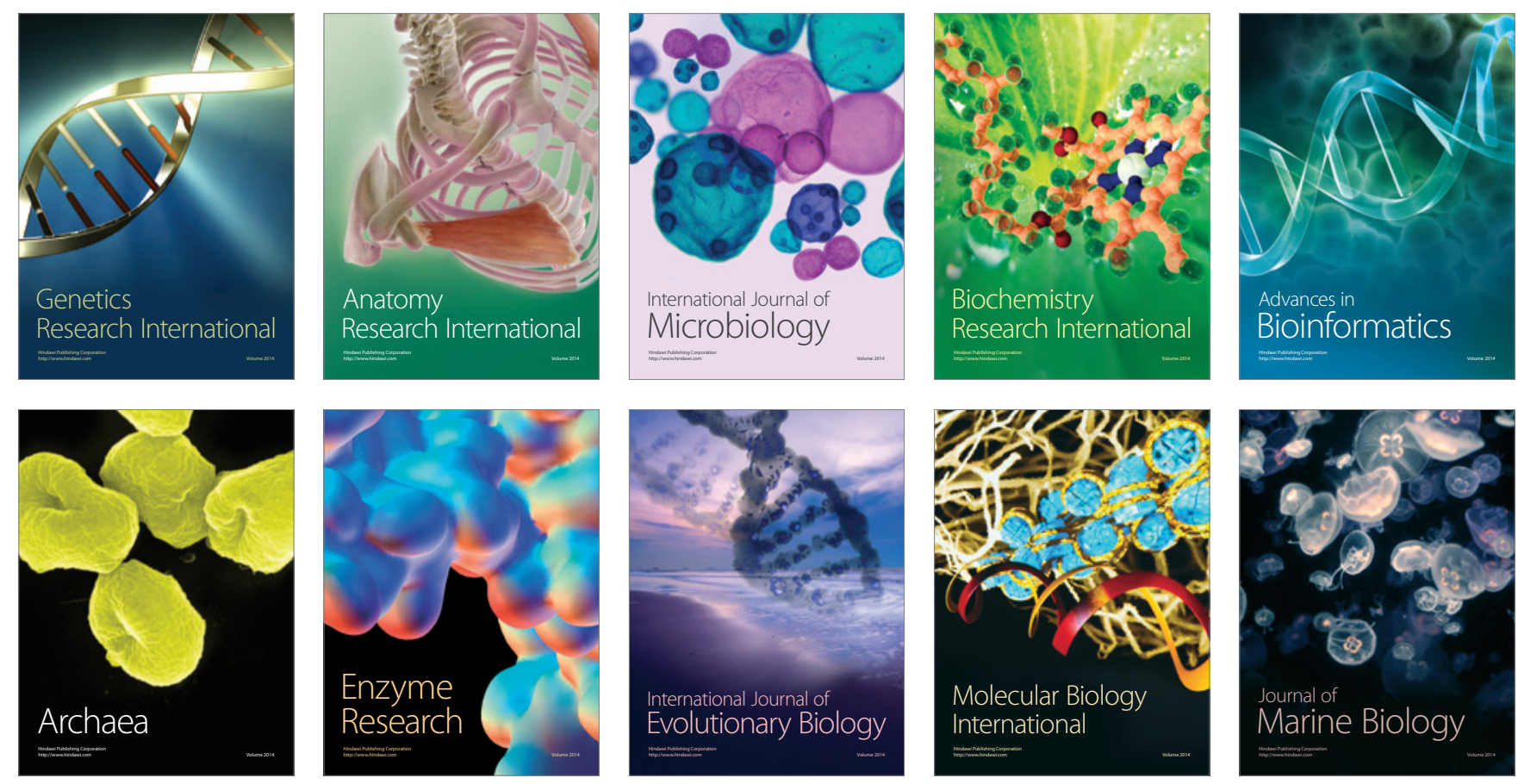